\section{3b REDUCING WORKERS EXPOSURES TO HIGHLY HAZARDOUS PESTICIDES WITH THE HIERARCHY OF CONTROL: LABELS FAILURE TO COMMUNICATE SAFETY BEHAVIOURS}

HA Rother. Division of Environmental Health, School of Public Health and Family Medicine, University of Cape Town, Observatory, South Africa

\subsection{6/oemed-2018-ICOHabstracts.1348}

'Misuse' of pesticides by agricultural workers assumes that these workers have access to the relevant risk information, are able to read the information, and are able to comprehend and apply this information. The main source of risk, health and safety information for workers is the pesticide label. Research conducted with South African farm workers highlights that health and safety label information is often not noticed and mis-interpreted from the expert intended meanings since workers have limited access to comprehension mechanisms. The Globally Haromonized System of Classification and Labelling of Chemicals (GHS) has been presented as a mechanism for improving label comprehension, but so far research has indicated that label information (e.g., in the form of icons/pictograms and colour codes) despite being harmonised is not understood to provoke the intended safety behaviours. With label information being a poor risk communication vehicle, it is argued that the Hierarchy of Control (HoC), originating from occupational hygiene, should be applied to the use of pesticides and for protecting the health and safety of workers to reduce hazardous exposures. The stages of the HoC are presented (i.e., elimination, substitution, engineering, administrative, behaviour and personal protective equipment) in order of effectiveness for protecting workers and examples applied. The United Nations Food and Agricultural Organisation (FAO), in conjunction with the WHO, are promoting the identification and management of Highly Hazardous Pesticides (HHPs). The eight criteria for identifying HHPs appear to be an effective approach to eliminating pesticides too hazardous for workers unable to understand label information to be exposed to. 'Misuse' of pesticides, it is argued, should therefore be referred to as 'unintended uses' to avoid blaming workers who do not have access to risk, health and safety information (i.e., right-to-know) and/or are unable to interpret the messages as scientifically intended (i.e., 'right-to-comprehend').

\section{C AGRICHEMICAL EXPOSURE IN AUSTRALIAN FARMERS - MONITORING, MEASURING AND MAKING A DIFFERENCE}

\footnotetext{
1,2Susan Brumby, ${ }^{2}$ Jacquie Cotton, ${ }^{1}$ Tam Phillips, ${ }^{2}$ Sienna Russell-Green, ${ }^{3}$ John Edwards. ${ }^{1}$ National Centre for Farmer Health, Western District Health Service, Hamilton VIC Australia; ${ }^{2}$ Deakin University School of Medicine, Waurn Ponds, VIC Australia; ${ }^{3}$ Flinders University, School of the Environment, Adelaide SA Australia
}

\subsection{6/oemed-2018-ICOHabstracts.1349}

Exposure to organophosphates at low levels over time has been associated with neurological conditions. In-field Personalised Cholinesterase Assessment Project (PCAP) is identifying the effect on cholinesterase (ChE) inhibition in Victorian (Australia) farmers caused by the application of organophosphates (OPs) and ChE inhibiting insecticides. Accurate field assessment is particularly important for remote rural communities and current available measurement does not accurately estimate individual risk. Funded by the Shepherd Foundation and commencing in April 2016 this work trials an innovative, transportable assessment tool, identifying farmers with reduced ChE activity, who are at risk of neurological symptoms and/or unknown chronic low level exposure. Using oxime regeneration to stimulate recovery $\mathrm{ChE}$ in vitro-a more accurate and meaningful estimate of the percentage inhibition of cholinesterase-is generated for the farmer. This new approach will provide farmers with instant results from a measurement tool using their own ChE inhibition range. Validated across 10 time points in 5 Victorian farming locations, the study involves 61 farmers and agricultural workers (crop and/or livestock) aged between $20-75$ years. This presentation will discuss the results generated using this novel, objective and portable field test including post participation behavioural changes. This research is providing farmers with fast evidence of personal exposure through individual results. This is leading to practice change, attitude shift, prevention of further exposures and possible reduction or change of pesticide use.

\section{3d PROTECTION OF WORKERS IN AGRICULTURE AGAINST EXPOSURE TO PESTICIDES AT WORK}

Shengli Niu. International Labour Organisation, Geneva, Switzerland

\subsection{6/oemed-2018-ICOHabstracts. 1350}

Introduction Exposure to agrichemicals poses an increasing health risk in agricultural work. Pesticide sales and use have continued to climb over the years. In developing countries, workers and farmers face greater risks due to the use of toxic chemicals - which are banned or restricted in other countries - incorrect application techniques, poorly maintained equipment, inadequate storage practices, and the reuse of old chemical containers for food and water storage. The end users often do not have access to information on the risks associated to the use of chemicals and on the necessary precautions and correct dosage. The total number of pesticide poisonings has been estimated between 2 and 5 million per year, of which 40000 are fatal.

Methods Description of the ILO activities on the protection of agricultural workers against exposure to pesticides at workplace.

Results The ILO uses various means of action to give governments and employers' and workers' organisations the necessary help in drawing up and implementing programmes for the control of workplace risk factors including pesticides. These means include international standards in the form of legal instruments, codes of practice, practical manuals, training materials and education and training and technical cooperation. They include the Safety and Health in Agriculture Convention (No. 184) and Recommendation (No. 192), 2001, and the List of Occupational Diseases Recommendation, 2002 (No. 194). The ILO code of practice on Safety and Health in Agricultural Work (1965), the Code of Practice on Safety and Health in Agriculture (2010), the ILO Encyclopaedia of Occupational Health and Safety, and the ILO Safety and Health in the use of Agrochemicals - A guide are just a few examples which have sections devoted to protection of workers against exposure to pesticides. The ILO collects information on good workplace practice on occupational safety and health and on the identifications and recognition of diseases as occupational caused by pesticides and provides support for the applications of the relevant ILO instruments in member States. The ILO develops guidance notes on the diagnostic and exposure criteria for occupational diseases caused by pesticides. 